\title{
Ética, Política e Práticas Profissionais
}

\section{Ethics, Politics and Professional Practices}

\author{
Ética, Política y Prácticas Profesionales
}

\author{
Neuza Maria de Fátima Guareschi \\ Universidade Federal do Rio Grande do Sul, Porto Alegre, RS, Brasil
}

É com grande satisfação que abrimos o Editorial de nossa primeira edição de 2018 desejando que este ano que se inicia seja de muita paz, alegrias, realizações pessoais e profissionais, mas, especialmente, de mudanças sociais, políticas e éticas para o Brasil. Vivemos o ano que passou assistindo ao desenrolar de práticas políticas de governantes que prescindiram cada vez mais de um estado de direito, da participação de seus cidadãos nas instituições e espaços públicos, mas, principalmente, assistindo à falta de ética de uma cúpula política e administrativa do país na gestão de bens e de recursos públicos, que levam os cidadãos a uma vida indigna e desumana. Assim, pensamos que a ética e a política, indissociáveis da nossa prática profissional, seja ela na produção do conhecimento ou nas diferentes atividades institucionais as quais nos vinculamos, possam ser vetores de mudanças que visam à garantia de direitos e à participação democrática em todas as relações sociais.

Certamente, o tema da ética foi um dos que mais ocuparam as discussões políticas nas diferentes esferas da nossa sociedade no ano que passou. Como já referenciado, a impossibilidade de uma separação entre a ética e a política nos leva a pensar que estas duas também são indissociáveis da ciência e, por sua vez, da produção de conhecimento ou de qualquer prática profissional. O número 31 do jornal Entre Linhas, do Conselho Regional de Psicologia do Rio Grande do Sul (CRP-RS), em 2005, já dedicava um número especial sobre ética e Psicologia. Neste número, seus editores, debatendo a mudança do código de ética do profissional em Psicologia, recém-ocorrida, afirmavam que este profissional deveria sempre atuar com responsabilidade ética, não dissociando a prática profissional de uma prática também política. Silveira e Huning (2008) colocam a disposição como "um componente ético que interfere diretamente em nossas disposições epistemológicas”, porém, que esta disposição "tem de ser convertida aqui em um problema de disposição ética para o entendimento no seio da diversidade e para a formação do diálogo". Acredito que na sociedade em geral e, frente à diversidade cultural, social racial e sexual, esta disposição também deva ser pensada como uma disposição política em relação à aceitação da vida do outro.

Freire (2003, p. 13-14), ao fazer uma análise sobre ao código profissional do psicólogo anterior ao atual, dizia que este tinha mais a ver com um código de postura profissional do que uma discussão sobre ética e cidadania. Refletindo sobre a prática profissional em Psicologia, este autor coloca que podemos pensar em duas evidências sobre esta prática: "A primeira, de que a toda prática psicológica subjaz um modelo ético específico sujeito às injunções da própria teorização a que se coaduna; a segunda, de que uma ética particular - a ética do trabalho psicológico - se coloca no lugar de rectora de toda e qualquer atuação profissional. Aqui e ali podemos vislumbrar conflitos na relação entre essas duas orientações éticas". Freire recorre a Levinas para dizer que há, conforme colocado por este filósofo, "uma alteridade radical que não pode ser negada ou denegada e que me intima a assumir uma responsabilidade absoluta para com todos os outros. Essa é a dimensão ética por excelência, a do estar a serviço de Outrem, por ele e para ele”. Desta forma, uma refle- 
xão sobre ética, política e a prática profissional em Psicologia é extremamente oportuna e bastante associada à crise da democracia que vivemos hoje em nosso país referido no primeiro parágrafo deste editorial. Um dos exemplos do não respeito à diversidade, a diferença, ou de que a prática profissional precisa ser pensada para a alteridade e não para um seqüestro e tortura deste outro, é a situação que o Conselho Federal de Psicologia (CFP) enfrenta neste momento, com a decisão judicial que descaracterizou a Resolução ${ }^{\circ}$ 001/1999.

A revista Psicologia: Ciência e Profissão apresenta, na edição 38.1, 13 artigos, sendo nove relatos de pesquisas e quatro estudos teóricos. $\mathrm{O}$ artigo que abre esta edição e que também inspirou o tema deste editorial remete às questões éticas na prática do profissional no campo da Psicologia. Os outros 12 artigos que vêm na sequência não deixam de abordar questões éticas e políticas da nossa prática profissional em relação à vida do outro. Assim, o artigo que tem por título "Análise dos Processos Éticos Publicados no Jornal do Conselho Federal de Psicologia", de autoria de Priscila Zaia, Karina da Silva Oliveira e Tatiana de Cássia Nakano, pensando na importância dos Conselhos Regionais e do CFP, relaciona-se com as tentativas de zelo com o cumprimento integral das práticas éticas da profissão e apresenta uma análise dos processos éticos publicados no período de 2004 a 2016 no Jornal do Federal. Foram avaliadas 26 edições, as quais apresentaram 286 infrações na seção intitulada "Processos éticos". Destaca-se que os três números mais recentes da revista apresentaram com maior clareza o conteúdo das ementas, tornando possível verificar que, dos 57 processos éticos descritos, 34 foram relacionados à área da avaliação psicológica, representando $60 \%$ do total dos respectivos números. Conclui-se que há uma demanda de ações voltadas à formação e à prática de profissionais da Psicologia.

Os próximos quatro artigos que apresentamos possuem em comum a temática da infância, embora sejam desenvolvidos a partir de diferentes perspectivas teóricas e metodológicas e com crianças de diversas faixas etárias. O primeiro deles, intitulado "Dificuldades Vivenciadas pelas Mães na Hospitalização de seus Bebês em Unidades Neonatais", de autoria de Leidimara Cristina Zanfolim, Ednéia Albino Nunes Cerchiari e Fabiane Melo Heinen Ganassin, propõe-se a descrever os sentimen- tos e dificuldades que as mães vivenciam durante a hospitalização do seu filho, por meio de um estudo qualitativo, com abordagem de pesquisa-ação e tendo como cenário o setor de Neonatologia do Hospital Universitário. A amostra foi constituída por 52 mães e os resultados foram divididos em três categorias: i) instituição hospitalar; ii) profissionais de saúde e iii) família, as quais indicam a importância de se entender que o sofrimento das mães vai além de questões relacionadas à patologia do bebê. O segundo artigo, de autoria de Ronaldo Freitas Oliveira, Marina Bento Gastaud e Vera Regina Röhnelt Ramires, tem como objetivo apresentar um estudo exploratório, de levantamento, transversal, para identificar experiências de psicoterapeutas de crianças brasileiras quanto às formas de inclusão dos pais no tratamento. O artigo intitulado "A Participação dos Pais na Psicoterapia da Criança: as Práticas dos Psicoterapeutas" foi realizado com 76 psicólogos através de um questionário on-line, sendo predominantemente mulheres, residentes na região sul, com até três anos de experiência clínica. Os resultados apontam que a inclusão dos pais na psicoterapia, em entrevistas específicas, para acolhimento, coleta de informações, aconselhamento ou orientação fortalece a aliança terapêutica. Riscos ou benefícios da participação dos pais dependem, entretanto, da dinâmica familiar e dos sintomas da criança.

Os próximos dois artigos deste bloco de quatro que possuem a temática da infância são desenvolvimentos através de instrumentos como um teste e uma escala psicológica. O artigo "WISC-III: Instrumento para Confirmação de Altas Habilidades ou Superdotação", de autoria de Lurian Dionizio Mendonça, Olga Maria Piazentin Rolim Rodrigues e Vera Lúcia Messias Fialho Capellini, utilizou o WISC-III para confirmar o alto desempenho intelectual em alunos identificados com indicadores de altas habilidades ou superdotação. Foram avaliados com o WISC-III 74 alunos dos anos iniciais do ensino fundamental de uma escola estadual do interior do estado de São Paulo. Foram confirmados 11 alunos e identificados 14 que obtiverem pelo menos um QI superior no WISC-III e que precisam de uma observação mais cautelosa, uma vez que apresentaram resultados superiores em comparação aos demais. Já o artigo "Escala de Perspectiva de Futuro Infantil: Evidências de sua Adequação Psicométrica”, de 
autoria de Ana Karla Silva Soares, Maria Gabriela Costa Ribeiro, Alessandro Teixeira Rezende, Tátila Rayane de Sampaio Brito e Valdiney Veloso Gouveia, teve como objetivo elaborar uma medida de perspectiva de futuro infantil, reunindo evidências de validade fatorial e consistência interna. Para tanto, foram realizados dois estudos na cidade de João Pessoa. No estudo 1, participaram 203 estudantes do ensino fundamental com idade média de 11 anos, que responderam a Escala de Perspectiva de Futuro - Infantil - EPF-I. No estudo 2, foram 202 estudantes com idade média de 11 anos que responderam aos mesmos instrumentos. Conclui-se que este instrumento reúne evidências de validade fatorial e consistência interna, podendo ser empregado para mensurar a perspectiva de futuro em crianças.

Os próximos dois artigos possuem como foco comum o trabalho de cuidadores, porém, em instituições bem diferenciadas. $\mathrm{O}$ primeiro destes artigos tem como foco a realização de uma discussão teórica acerca do trabalho dos cuidadores residentes, atuantes em instituições de acolhimento na modalidade casa-lar. O artigo intitulado "O Estabelecimento de Vínculos em Instituições de Acolhimento: um Estudo Teórico", de autoria de Blenda Carine Dantas e João Batista Martins, busca contemplar as especificidades próprias ao trabalho realizado diretamente com crianças e adolescentes acolhidos, tanto no que diz respeito aos documentos normativos que fundamentam as práticas voltadas ao cumprimento dessa medida protetiva, como também em relação às vivências cotidianas dos cuidadores e as relações estabelecidas com os sujeitos acolhidos e seus familiares. A leitura dos artigos, teses e dissertações possibilitaram discutir algumas questões relativas ao trabalho de cuidadores residentes e ao estabelecimento de vínculos com as crianças e adolescentes acolhidos, com destaque para os tensionamentos vivenciados por esses profissionais, que podem levá-los ao adoecimento decorrente de seu trabalho. O segundo artigo tem como foco compreender os principais sentidos e significados atribuídos pelos cuidadores à experiência de acompanhamento de pacientes com câncer em cuidados ao fim de vida através de observação participante. Com o título "Cuidadores Principais Frente à Experiência da Morte: seus Sentidos e Significados", o artigo de autoria de Carolina Peres de Lima e Mariana de Abreu Machado aponta para os sentimentos expostos pelos cuidadores que, ape- sar do esgotamento físico e emocional, desejavam permanecer ao lado de seu familiar até sua morte. Indicam também que a comunicação da equipe ao cuidador sobre a aproximação da morte pode contribuir para o processo de elaboração psíquica desta experiência.

Os próximos três artigos também abordam a questão do trabalho, porém, de maneiras bem adversas em relação àquilo que este tema pode afetar a vida das pessoas. O primeiro destes três artigos trata de um fazer bastante específico na área dos esportes, ou seja, de árbitros de futebol e o estresse. Com o título "Estresse e Coping de Árbitros de Futebol no Teste Físico FIFA", o artigo de Alessandra Carla Peixoto Monteiro, Mariana Froeseler e Marcela Mansur-Alves tem por objetivo avaliar diferenças em coping e estresse negativo em uma amostra de árbitros atuantes em campeonatos estaduais e nacionais. Quarenta e dois árbitros da Federação Mineira de Futebol (FMF) e 17 da Confederação Brasileira de Futebol (CBF) responderam à Escala de Estresse Percebido, que avalia estresse negativo e coping, antes e após o teste físico da Fédération Internationale de Football Association (FIFA). Na avaliação pré-teste, verificou-se que os árbitros da CBF apresentaram histórico de mais testes físicos, treinos por semana, anos de experiência, além de escores mais altos em coping. Quando controladas as diferenças iniciais, os árbitros da CBF e da FMF não diferiram significativamente em coping e distress no pós-teste físico.

O segundo destes artigos discute a pertinência da relação entre fatores patogênicos na organização de trabalho e o desenvolvimento de doenças psicossomáticas em trabalhadores. De autoria de Lais Di Bella Castro Rabelo, Julie Micheline Amaral Silva e Maria Elizabeth Antunes Lima e intitulado: "Trabalho e Adoecimento Psicossomático: Reflexões sobre o Problema do Nexo Causal", apresenta o caso de uma trabalhadora do setor de teleatendimento que, em perícia na justiça do trabalho, recebeu hipótese diagnóstica de Episódio Depressivo associado a um Transtorno de Somatização com desenvolvimento de doença autoimune. Através de um paralelo entre a literatura específica e estudos de caso sobre Saúde Mental e Trabalho, o texto propõe uma reflexão acerca das consequências da vivência do estresse laboral na saúde física e mental dos trabalhadores, especialmente sobre suas reverberações no sistema imunológico. 
Abordando a teoria da "carreira sem fronteiras" como uma das que detêm maior credibilidade nos meios acadêmico e empresarial, o artigo "Os Limites e o Sucesso da 'Carreira sem Fronteiras'”, de Luciano Espósito Sewaybricker analisa a inconsistência desta teoria através do conceito de "performatividade" apresentado pela Actor-Network Theory. O autor avalia a "carreira sem fronteiras" não através de sua correspondência com a realidade, mas de sua reputação e influência no próprio cenário em que atua e, sobretudo, de sua eficiência em auxiliar as pessoas em seus cálculos cotidianos na relação com o trabalho. Identifica, contudo, que a simplificação teórica favorece a reprodução da "carreira sem fronteiras"; que o modelo teórico corresponde à realidade de uma parcela pequena, mas altamente influente de profissionais dentro do universo de trabalho.

Questões sobre o desenvolvimento e o amadurecimento psicológico das pessoas frente aos impactos do ambiente ou à necessidade de adaptação ao mundo externo são temas dos próximos dois artigos, porém, em contextos muito diferentes um do outro. O artigo "Diagnóstico Adaptativo e Individualização em Gêmeos: um Estudo Exploratório”, de autoria de Maria Elizabeth Barreto Tavares dos Reis, Silvia Nogueira Cordeiro e Ryad Simon, discute o amadurecimento afetivo-emocional no desenvolvimento do processo de individualização em gêmeos e a saúde psíquica em termos de capacidade de adaptação. Participaram do estudo 12 pares de gêmeos adultos do mesmo sexo, que foram entrevistados a respeito das histórias de vida e avaliados através da Escala Diagnóstica Adaptativa Operacionalizada Revisada (EDAO-R). Verificou-se que a maneira com que os cogêmeos foram percebidos, identificados e atendidos em suas necessidades específicas contribuiu significativamente para que a individualização e adaptação aos diversos setores da vida pudessem ou não ocorrer de forma eficaz.

Já o artigo "Reconstrução em Movimento: Impactos do Terremoto de 2010 em Imigrantes Hai- tianos", de autoria de Allyne Fernandes Oliveira Barros e Lucienne Martins-Borges tem como objetivo analisar quais os impactos psicológicos do terremoto que, além de levar a experiência do imprevisível pelo evento em si, foi seguido de uma migração necessária para a continuidade e reconstrução da vida. O estudo discute o processo das migrações involuntárias como aquele que implica em diversas mudanças e pode levar o sujeito a um estado de vulnerabilidade psíquica, pois muito daquilo que $o$ orientava em sua existência é ameaçado pelo contato com a cultura diferente. Os resultados demonstram que a lembrança traumática, as perdas de pessoas próximas, a casa, o trabalho e a educação foram acrescidos às dificuldades de uma migração é vivida com dificuldade de integração pela maioria desses sujeitos. Em contrapartida, o desejo de reconstrução da história individual e coletiva apresenta-se como importante força na vida dessas pessoas que, mesmo a distância, procuram compartilhar projetos com os conterrâneos.

Fechamos a edição 38.1 deste periódico com um estudo teórico com algumas teses gerais de Lacan sobre a linguagem que podem também fornecer e corroborar para uma abordagem discursiva do afeto. Com o título "Para uma Concepção Discursiva dos Afetos: Lacan e a Semiótica Tensiva”, o artigo de autoria de Tiago Ravanello, Christian Ingo Lenz Dunker e Waldir Beividas busca no diálogo com a semiótica tensiva, a partir dos conceitos de intensidade e extensidade, as diretrizes para reposicionar o afeto, em sentido restrito, e o ponto de vista econômico, em sentido amplo, em termos de uma semiose na qual corpo e linguagem contribuem para uma abordagem discursiva dos fenômenos em questão. Seguindo a forma pela qual Lacan formulou seu projeto epistemológico, os autores argumentam que não há condições de estabelecermos propostas teóricas ou hipóteses clínicas senão através do meio discursivo, que passa invariavelmente pela constituição do afeto nas operações que incidem sobre o sujeito em sua relação com o Outro. 


\section{Referências}

Batalha incansável. (2005). Entre Linhas, 6(31), 2.

Freire, J. C. (2003). A Psicologia a serviço do outro: Ética e cidadania na prática psicológica. Psicologia: Ciência e Profissão, 23(4), 12-15. https://doi.org/10.1590/S1414-98932003000400003

Silveira, R. A. T., \& Hüning, S. M. (2008). A angústia epistemológica na psicologia. Psicologia: Teoria e Pesquisa, 23(4), 473-480. https://doi.org/10.1590/S0102-37722007000400014

Neuza Maria de Fátima Guareschi

Universidade Federal do Rio Grande do Sul

Editora

Email: neuza.guareschi@cfp.org.br

Como citar:Guareschi, N. M. F. (2018). Ética, política e práticas profissionais [Editorial]. Psicologia: Ciência e Profissão, 38(1), 3-7. https://doi.org/10.1590/1982-3703003812018

How to cite: Guareschi, N. M. F. (2018). Ethics, politics and professional practices [Editorial]. Psicologia: Ciência e Profissão, 38(1), 3-7. https://doi.org/10.1590/1982-3703003812018

Cómo citar: Guareschi, N. M. F. (2018). Ética, política y prácticas profesionales [Editorial]. Psicologia: Ciência e Profissão, 38(1), 3-7. https://doi.org/10.1590/1982-3703003812018 